\title{
MORA RUIZ, Manuela, La gestión ambiental compartida: función pública y mercado, Lex Nova, Valladolid, 2007, 428 páginas.
}

El libro de la Dra. Manuela Ruiz, titulado La gestión ambiental compartida: función pública y mercado, aborda un tema de gran interés para el moderno Derecho ambiental como es el de la gestión ambiental compartida, un nuevo modelo de tutela ambiental, complementario de la función pública de protección ambiental y que pone el acento en el mayor protagonismo de los sujetos privados en la tutela de este bien jurídico.

El objetivo principal de esta obra es, pues, la gestión ambiental compartida, que como afirma la propia autora, "se convierte en el marco general en el que las técnicas más novedosas de tutela ambiental van a poder desenvolverse, constituyendo, a su vez, una referencia ineludible de enfoques alternativos del Derecho Administrativo en lo que a las relaciones entre ciudadanos y Administración se refiere” (p. 22). A lo largo de este libro la autora proporciona multitud de elementos de juicio y argumentos a favor de un esquema de gestión del medio ambiente de carácter compartido, donde función pública y mercado vayan de la mano y donde actores públicos y privados se involucren, a través de nuevas técnicas de protección del medio ambiente y con diferentes roles, en el objetivo de alcanzar el máximo nivel de calidad ambiental. Y éste es el hilo conductor de la obra.

Esta monografía se divide en cinco capítulos interrelacionados, aunque diferenciados por la perspectiva adoptada. El primero de ellos, de carácter más introductorio, lleva por título "La puesta en cuestión de la función pública de tutela ambiental: bases para su necesaria actualización". En él se analizan, en primer lugar, la tutela ambiental como función pública y sus caracteres fundamentales; así como algunos de los tradicionales mecanismos de intervención administrativa en aras de la protección del bien jurídico ambiente, como la fijación de objetivos de calidad y la autorización administrativa. En segundo lugar, tras destacarse la necesidad de incorporar una cierta flexibilidad en la exigencia del cumplimiento de obligaciones derivadas de la legislación ambiental, se aportan algunos ejemplos de actualización de la función pública de tutela ambiental. Concretamente, se estudian la autorización ambiental integrada, regulada por la Ley 16/2002, de 1 de julio, de prevención y control integrados de la contaminación; y la 
comunicación con posibilidad de prohibición para el supuesto de actividades de baja incidencia ambiental.

En el capítulo siguiente, Manuela Mora se adentra en el análisis de los principios que podrían fundamentar una nueva categoría de técnicas de tutela ambiental. En este contexto, trae a colación los principios de desarrollo sostenible, de participación y de responsabilidad compartida. Pero lo realmente interesante es el análisis que realiza del principio de cooperación entre ciudadanos y Administración, el contexto en el que nace, su definición, sus caracteres y su ámbito de aplicación. En su opinión, la orientación que representan los principios ambientales citados "para la modificación de las estrategias de protección ambiental, en cuanto a invalidar un modelo basado en la exclusiva responsabilidad de la Administración para la satisfacción de la aludida función de tutela ambiental, encuentra un fundamento de carácter general en el que en este Trabajo se denomina principio de cooperación" (p. 113). Desde esta perspectiva, "la cooperación constituye el marco a partir del cual los instrumentos de mercado que se proponen como renovadores de la función de protección ambiental cobran pleno significado, puesto que dicho principio conecta con un proceso generalizado en los sectores económicos o de carácter prestacional en virtud del cual la participación de los ciudadanos en la satisfacción del interés general se intensifica y adquiere perfiles propios, propiciando un proceso de privatización que da carta de naturaleza a una gestión del medio ambiente compartida entre Administración y ciudadanos, titulares todos del bien jurídico que nos ocupa" (p. 114). Este capítulo se cierra con una primera aproximación a los instrumentos de mercado de carácter cooperador, como concreción del principio de cooperación entre ciudadanos y Administración para la gestión de intereses generales.

Tras esta contextualización general, el capítulo tercero analiza en profundidad el régimen jurídico de los instrumentos de mercado de carácter cooperador que, a diferencia de los instrumentos tradicionales, “indican una dirección al permitir y necesitar la conducta activa de todos los sujetos relacionados con el bien jurídico ambiente, fijando, pues, el horizonte de este Derecho en la cooperación" (p. 289). En particular, son cuatro los instrumentos objeto de análisis: el permiso negociable y, en particular, el mercado de emisiones de $\mathrm{CO}$; la etiqueta ecológica europea; el sistema comunitario de gestión y auditorías ambientales (EMAS); y los acuerdos y convenios ambientales. 
El capítulo siguiente se dedica a la identificación y consideración de los rasgos definidores de la gestión ambiental compartida. En él se examinan los nuevos escenarios de la tutela ambiental y, en particular la europeización del Derecho administrativo ambiental y el mercado; y la relación jurídico-administrativa como clave de una tutela ambiental plural, analizándose la posición de los diferentes actores (agente contaminador, Administración, sujetos intervinientes y público). Por último, la autora se hace eco de la importancia y de la operatividad de la información ambiental en la gestión compartida del medio ambiente.

Se cierra la monografía con el capítulo quinto. En él se abordan los efectos y consecuencias del nuevo modelo de gestión ambiental compartida. La autora distingue un doble orden de efectos de este nuevo enfoque en la tutela ambiental. Por una parte, se refiere a las consecuencias de carácter inmediato, relacionadas, como ella misma afirma, "con las transformaciones que se producen en los roles asumibles por cada uno de los sujetos involucrados en la protección del medio ambiente" (p. 23); y, en este contexto, analiza tanto el reparto de competencias y la organización administrativas en la gestión ambiental compartida como las nuevas categorías del Derecho administrativo en clave de cooperación entre ciudadanos y Administración. Por otra, a las consecuencias de carácter mediato, que la llevan a efectuar interesantes reflexiones sobre aspectos de la gestión ambiental compartida relacionados con el acto administrativo, el procedimiento administrativo y la responsabilidad por daños al medio ambiente. Finalmente, concluye este capítulo con un análisis de los pros y contras de la gestión compartida en tanto que motor de renovación de la función de tutela ambiental. Para la autora "la gestión ambiental compartida es una alternativa para la configuración tradicional del Derecho Administrativo Ambiental y es, a la vez, un reto. Las bases del mismo están puestas: resta su consolidación” (p. 397).

El libro de Manuela Mora supone, en definitiva, una valiosa contribución para el estudio del moderno Derecho ambiental - caracterizado, como pone de manifiesto la autora, por una gran interacción entre mercado y derecho-, que enriquece de forma significativa las aportaciones doctrinales hasta ahora existentes al respecto. Como pone de manifiesto el profesor José Ignacio López en el prólogo que realiza a esta obra, la autora ha sabido "destacar y analizar con acierto toda esta realidad del moderno Derecho Ambiental, que 
sintetiza bajo el nuevo concepto de "gestión ambiental compartida", definidor de uno de los rasgos más característicos y originales del actual Derecho ambiental” (p. 11).

En este trabajo se pueden encontrar, además de un completo análisis de los instrumentos de mercado de carácter cooperador como nueva categoría de técnicas de tutela ambiental, interesantes reflexiones en torno a los nuevos escenarios de la tutela ambiental y la gestión ambiental compartida.

Además, es preciso destacar que, frente a la complejidad que acompaña a muchas de las cuestiones que aborda, la autora tiene la virtualidad de utilizar un estilo claro, sencillo, de agradable lectura y comprensión para el lector, lo cual constituye, indudablemente, un mérito más de esta excelente obra.

En suma, estamos ante un libro interesante y bien trabajado, cuya lectura debe recomendarse. La gestión ambiental compartida: función pública y mercado resulta imprescindible tanto para quienes deseen conocer en profundidad el Derecho ambiental y sus tendencias evolutivas, como para aquellos que deseen conocer algunas de las principales líneas de evolución de ciertas instituciones del Derecho administrativo. Efectivamente, con el telón de fondo de la protección ambiental, este trabajo aborda cuestiones generales del Derecho público y nos sitúa en la evolución y actualización del propio Derecho administrativo.

Lucía Casado Casado

Profesora Titular de Derecho Administrativo Investigadora del Centre d'Estudis de Dret Ambiental de Tarragona Universitat Rovira i Virgili 